\title{
In-house Standard Method for Molecular Characterization of Dissolved Organic Matter by FT-ICR Mass Spectrometry
}

Chen $\mathrm{He}^{\dagger, ",}$, Yahe Zhang ${ }^{\dagger, "}$, Yunyun $\mathrm{Li}^{\dagger}$, Xiaocun Zhuo ${ }^{\dagger}$, Yuguo $\mathrm{Li}^{\dagger}$, Chuanlun Zhang ${ }^{\dagger, \ddagger}$, Quan $\mathrm{Shi}^{\dagger *}$

†State Key Laboratory of Heavy Oil Processing, Petroleum Molecular Engineering Center (PMEC), China University of Petroleum, Beijing 102249, China

${ }^{\ddagger}$ Shenzhen Key Laboratory of Marine Archaea Geo-Omics, Department of Ocean Science \& Engineering, Southern University of Science and Technology, Shenzhen 518055, China

\section{Key parameters of the FT-ICR MS}

Many factors relevant to the mass spectrum. It is important to consider the specific structure of the instrument, in order to optimize parameters for achieving a high quality mass spectrum. The principle and instrumental parameters of FT-ICR MS have been reviewed by Marshall et al. (Mass spectrometry reviews, 1998, 17(1): 1-35.). Here, we give a brief discussion of the key parameters affecting the mass spectrum with the Apex-Ultra FT-ICR MS (Figure S1). The value ranges of these parameters were shown in Table S1.

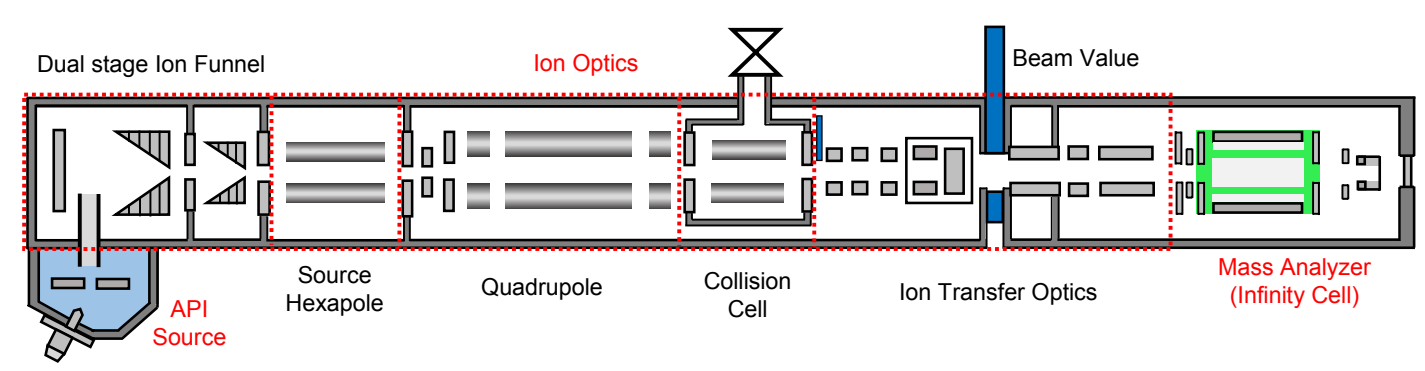

Figure S1. Schematic diagram of the Apex-Ultra FT-ICR MS. 


\section{Ionization (Electrospray Ionization)}

In the low nebulizer gas flow, the mass spectrometry signal intensity is low, while the signal is not stable in the high nebulizer gas flow. The flow and temperature of dry gas have a relative small effect on the signal intensity, so the adjustable range of them are wide. The ionization voltages including spray shield voltage and capillary column introduced voltage have significant effects on the signal intensity of the DOM samples. Considering the most components of DOM are polar compounds and easy to be ionized, the ionization voltage should not be too high. For DOM samples, the nebulizer gas flow, dry gas flow, and ionization voltage should be regulated simultaneously to control the capillary current around at 10-40 mA for high ionization efficiency in negative-ion ESI mode.

\section{Ion Transmission (Ion Optics)}

Skimmer2 of the dual stage ion funnel has severe effect on the mass distribution. In the appropriate voltage range, the higher value of Skimmer2 is benefit for the ion transmission with higher molecular weight. The HexDC bias voltage, source hexapole trap voltage and extract voltage have little effect on the the signal intensity. The setting of the Q1 value is critical because the optimization of RF and DC voltage on the quadrupole is base on this setting. Ions passed through the quadrupole have different transfer efficiency, discrimination is ineluctable for both ends of the mass range.

Accumulation time (CCA) and collision voltage in the collision cell (CV) have a great effects on the quality of the mass spectrum. In general, the signal intensity increases with the increase of CCA. However, overfill will effect the free motion of the accumulated ions with collision induced dissociation and lead to incorrect ion composition and mass distribution. The optimization on CCA is to select a time as long as possible with unchanged mass distribution and the multiplied signal intensity. The collision energy will cause the ions to undergo energetic collisions with the gas as they are accelerated into the collision cell. The resulting difference between Ion Funnel 2 and the collision cell pole bias voltages is termed the collision energy. The collision energy is increased by manipulating the collision voltage. DOM ions with carboxyl and hydroxyl groups are easy to form 
aggregation, so a low collision voltage is needed for the disaggregation.

Time for the ions to travel from the collision cell to the analyzer (TOF) is another critical parameter that affects the mass distribution. The ions are initially accelerated up to $\sim 3 \mathrm{kV}$ to focus them through the flow restriction between the differential pumping stages into the ultra high vacuum. After passing through the gap of the beam valve, ions are decelerated and focused through the inhomogeneous fringe field of the superconducting magnet before they reach the analyzer. However, it is difficult to trap both the small molecules and the large molecules very well simultaneously. The short TOF is conducive to the ion transmission with low $\mathrm{m} / \mathrm{z}$ ions, and vice versa.

\section{Detection (ICR Cell)}

In the Apex-Ultra line of instruments, detection and measurement of ions occur in the mass analyzer, the Infinity Cell, which is the core of FT-ICR MS. The analyzer is a cylindrical ion trap, located in the center of the superconducting magnetic field. Ions are confined radial by the high magnetic field and axial by two trapping electrodes at either end of the trap (trapping plates). Ions are accelerated to higher radii by means of rf excitation across two opposing electrodes (excitation plates). At the appropriate time the rf field is turned off and the now coherent package of ions is detected by another set of two opposing cylinder segments of the trap (detection plates). The ions which revolve around the axis of the homogeneous magnetic field with their individual cyclotron frequencies induce mirror current which is amplified by a preamplifier The parameters (such as sidekick, trapping voltage, excitation amp etc.) of ICR cell affect the mass weight distribution, mass resolution, and mass accuracy. Sidekick has the greatest impact on ion accumulation. The magnitude of the trapping potentials effect the ions cloud's radial position. Generally, the best performance is obtained with low trapping potentials $(<1.5 \mathrm{~V})$. Excitation amp, which is in inverse proportion to excitation power, has effects on mass resolution, peak intensity, and peak bifurcation. The greater the excitation power, the larger the ion radius which produces the strongest signal. Excitation powers which are too high, however, can result in lower resolution and low sensitivity due to radial ion loss. Generally, peak bifurcation at low molecular weight is results from excessive 
excitation power, and vice versa.

Acquisition size and low mass end of broadband detection have a great relationship with the mass resolution. For DOM samples, the mass range were set at $\mathrm{m} / \mathrm{z} 200-800$ and the mass spectra were recorded using $2 \mathrm{M}$ word data sets with a transient length of $1.5379 \mathrm{~s}$, and the theoretical mass resolution could reach to 530000 at $\mathrm{m} / \mathrm{z} 400$. 
Table S1. Key operating parameters of the Apex Ultra FT-ICR MS

\begin{tabular}{|c|c|c|c|}
\hline & Parameter & Values & Unite \\
\hline Syringe pump & Flow rate & $180 \sim 250$ & $\mu \mathrm{L} / \mathrm{min}$ \\
\hline \multirow{5}{*}{ API source } & Capillary & $4200 \sim 3700$ & V \\
\hline & Spray Shield & $3700 \sim 3200$ & V \\
\hline & Neb gas Flow & $1.8 \sim 2.5$ & $\mathrm{~L} / \mathrm{min}$ \\
\hline & Dry Gas Flow & $3.5 \sim 5$ & $\mathrm{~L} / \mathrm{min}$ \\
\hline & Dry Temp & 200 & ${ }^{\circ} \mathrm{C}$ \\
\hline \multirow{13}{*}{ Ion optics } & Capillary exit voltage & -300 & V \\
\hline & Deflector plate voltage & -280 & V \\
\hline & Funnel 1 voltage & -160 & V \\
\hline & Skimmer 1 voltage & -25 & V \\
\hline & Funnel RF amplitude & 200 & Vpp \\
\hline & Funnel 2 voltage & -15 & V \\
\hline & Skimmer 2 voltage & $-7 \sim-5$ & $\mathrm{~V}$ \\
\hline & Q1 mass & 300 & $m / z$ \\
\hline & Hexapole RF amplitude & 350 & Vpp \\
\hline & Ion accumulation time in the hexapole & 0.001 & $\mathrm{sec}$ \\
\hline & Accumulation time in the collision cell & $0.1 \sim 0.5$ & sec \\
\hline & Ion flight time into the ICR cell & $1.0 \sim 1.2$ & $\mathrm{~ms}$ \\
\hline & Collision voltage in the collision cell & 1.5 & V \\
\hline \multirow{6}{*}{ Mass analyzer } & Analyzer entrance voltage & 2 & $\mathrm{~V}$ \\
\hline & Sidekick voltage & -10.5 & V \\
\hline & Sidekick offset voltage & 6 & V \\
\hline & Front trap plate voltage & $-0.9 \sim-0.95$ & V \\
\hline & Back trap plate voltage & $-0.95 \sim-1.0$ & V \\
\hline & Excitation amp & $13.5 \sim 15$ & $\mathrm{~dB}$ \\
\hline
\end{tabular}


Standard Methods of State Key Laboratory of Heavy Oil Processing HOP 002-2019

\section{Standard Test Method for \\ Molecular Characterization of Dissolved Organic Matter by Negative-ion ESI FT-ICR MS}

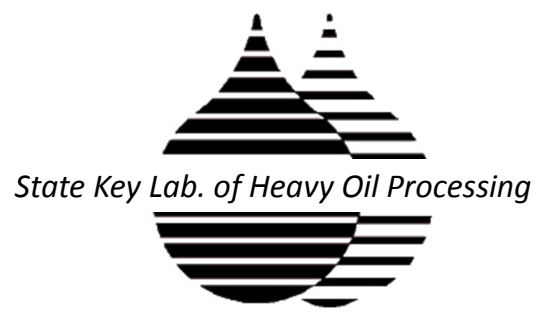

State Key Laboratory of Heavy Oil Processing

China University of Petroleum, Beijing

April, 2019 


\section{Scope}

1.1 This test method covers the analytical method and quality requirements for the molecular characterization of dissolved organic matter (DOM) by Fourier transform ion cyclotron resonance mass spectrometry (FT-ICR MS) coupled with negative-ion Electrospray ionization (ESI).

1.2 This test method covers the determination of various types of natural water system (seawater, river water, lake water, groundwater, rainwater, pore water, glaciers), drinking water, sewage, and DOMs from soil, sediment, and aerosols.

\section{Referenced Documents}

GB/T 6041-2002 General rules for mass spectrometric analysis

JJF 1317-2011 Calibration Specification for Liquid Chromatography-Mass Spectrometers

SY/T 6563-2003 Regulation for use and management of dangerous chemical reagent

SY 6014-2010 Safety regulations for petroleum laboratory

\section{Quality control Sample}

This test method selects Suwannee River Fulvic Acid (SRFA) from International Humic Substance Society (IHSS) as the quality control sample.

\section{Apparatus}

\subsection{Mass spectrometer}

Bruker Apex-Ultra FT-ICR MS equipped with a 9.4 T superconducting magnet interfaced with negative-ion mode electrospray ionization.

4.2 Sample Inlet System

Single Syringe Pumps

\section{Summary of Test Method}

The principle of this test method is taking the mass spectrum quality of the SRFA as the control target to make reproducible results. The mass spectrum profile, peak shape, resolution, and relative intensity distribution of the SRFA were adjusted by optimizing the operating conditions. Only all the requirements of these aspects are well met, the instrument can be used for the real sample analysis. 


\section{Reagents and Materials}

6.1 Methanol. (Warning-Poisonous. Operate in the fume hood.)

6.2 Glass syringe: $250 \mu \mathrm{L}$, sample bottle: $2 \mathrm{~mL}$, pipette: $1.0 \mathrm{~mL}$.

\section{Sample preparation}

The SRFA was dissolved in methanol at a concentration of $100 \mathrm{mg} / \mathrm{L}$, with ultrasonic treatment for 10 minutes before MS analysis.

\section{Analytical procedure}

8.1 Make sure the mass spectrometer is working properly.

8.2 Clean sample inlet system with methanol.

8.3 Solvent blank. Using methanol as the solvent, acquire the spectrum to make sure the interference in the blank is acceptable.

8.4 Optimize the operating parameters. Inject sample, adjust instrumental parameters, until the mass spectrum of SRFA is met the analysis requirements.

8.5 Run sample analysis.

\section{Quality requirements for the mass spectrum of SRFA}

9.1 Free induction decay (FID)

FID signal keep a continuous decay within the full transient time (Figure 1).

9.2 Mass resolution

The mass resolution at $\mathrm{m} / \mathrm{z} 371.0620$ (corresponding to $\left[\mathrm{C}_{15} \mathrm{H}_{16} \mathrm{O}_{11}-\mathrm{H}\right]^{-}$) should be not less than 280000 (Figure 2).

9.3 Relative peak intensity

The peaks with $\mathrm{S} / \mathrm{N}$ greater than 20 in the overall mass spectrum should be unsplit and symmetric (Figure 2).

\subsubsection{Isobaric peaks at $m / z 371$}

Four peaks at $\mathrm{m} / \mathrm{z} 371$ were used to evaluate the spectrum. The base peak at $\mathrm{m} / \mathrm{z} 371$ is the quasi-molecular ion peak of $\left[\mathrm{C}_{16} \mathrm{H}_{20} \mathrm{O}_{10}-\mathrm{H}\right]$. The relative peak intensity ranges between the base peak and three other peaks of $\left[\mathrm{C}_{18} \mathrm{H}_{12} \mathrm{O} 9-\mathrm{H}\right]^{-},\left[\mathrm{C}_{15} \mathrm{H}_{16} \mathrm{O}_{11}-\mathrm{H}\right]^{-}$, and $\left[\mathrm{C}_{17} \mathrm{H}_{24} \mathrm{O}_{9}-\mathrm{H}\right]^{-}$were restricted at 
$23 \pm 8 \%, 83 \pm 10 \%$, and $54 \pm 10 \%$ (Table 1), respectively. At the same time, the minimum S/N value of these four peaks was restricted as shown in Table 1. In addition, the $\mathrm{S} / \mathrm{N}$ value of the quasimolecular ion peak of $\left[\mathrm{C}_{22} \mathrm{H}_{28} \mathrm{O} \mathrm{O}_{5}-\mathrm{H}\right]^{-}$should be not less than 6 .

9.3.2 Relative peak intensity of overall mass spectrum

The mass range of SRFA is between 200 to $700 \mathrm{Da}$ with a center of the normal distribution around $m / z 355$ (Figure 3). Seven peaks were selected to quantify the ratio of peak intensity of overall mass spectrum. These seven peaks were 251.0197, 311.0772, 355.1034, 411.0932, 463.0517, 519.0418, and 573.0524, which corresponding to ions of $\left[\mathrm{C}_{11} \mathrm{H}_{8} \mathrm{O}_{7}-\mathrm{H}\right]^{-},\left[\mathrm{C}_{14} \mathrm{H}_{16} \mathrm{O} \mathrm{O}_{8}-\mathrm{H}\right]^{-}$, $\left[\mathrm{C}_{16} \mathrm{H}_{20} \mathrm{O} 9-\mathrm{H}\right]^{-},\left[\mathrm{C}_{18} \mathrm{H}_{20} \mathrm{O}_{11}-\mathrm{H}\right]^{-},\left[\mathrm{C}_{20} \mathrm{H}_{16} \mathrm{O}_{13}-\mathrm{H}\right]^{-},\left[\mathrm{C}_{22} \mathrm{H}_{16} \mathrm{O}_{15}-\mathrm{H}\right]^{-}$, and $\left[\mathrm{C}_{25} \mathrm{H}_{18} \mathrm{O}_{16}-\mathrm{H}\right]^{-}$, respectively. The selected seven peaks cover most of the mass range. The relative peak intensities and minimum $\mathrm{S} / \mathrm{N}$ values of these seven peaks are shown in Table 2 . In addition, the $\mathrm{S} / \mathrm{N}$ value of the quasimolecular ion peak of $\left[\mathrm{C}_{9} \mathrm{H}_{6} \mathrm{O}_{7}-\mathrm{H}\right]^{-}$(theoretical $\mathrm{m} / \mathrm{z} 225.0041$ ) and $\left[\mathrm{C}_{27} \mathrm{H}_{20} \mathrm{O}_{18}-\mathrm{H}\right]^{-}$(theoretical $\mathrm{m} / \mathrm{z}$ 631.0576) should be not less than 10 .

9.4 Mass accuracy

The mass accuracy of the nine peak mentioned in section 9.3 .2 should be within $0.5 \mathrm{ppm}$.

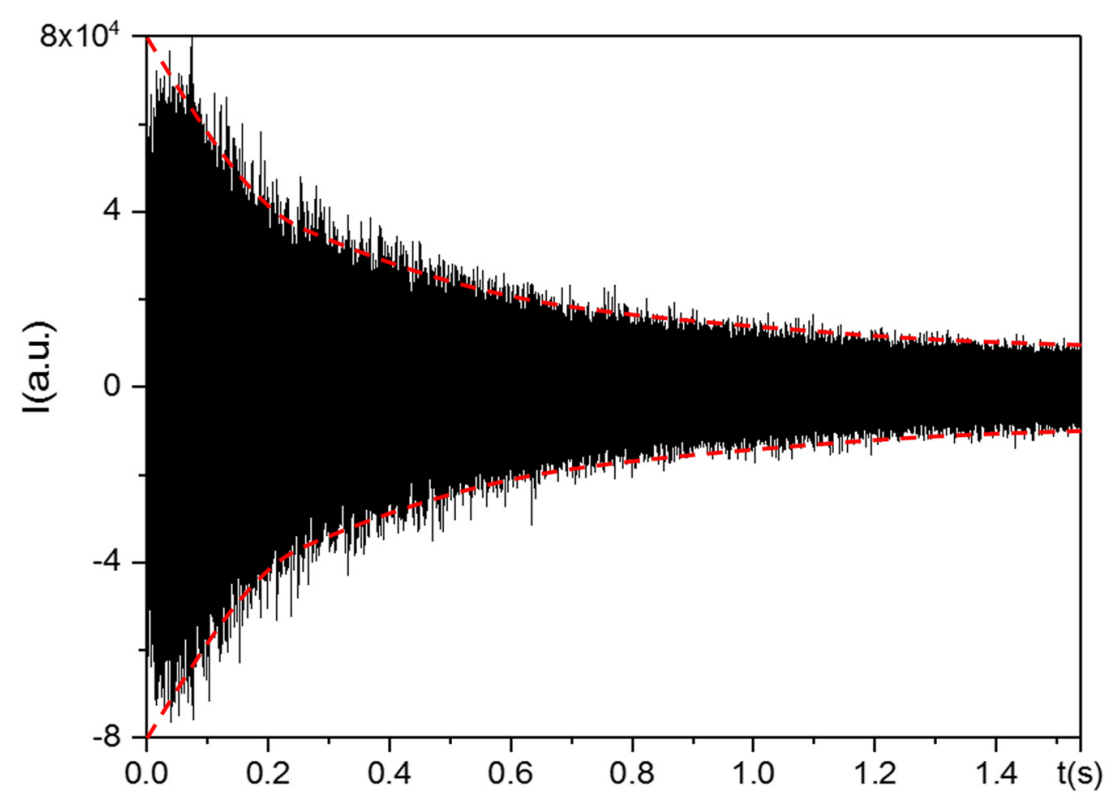

Figure 1. Time-domain free induction decay of SRFA 


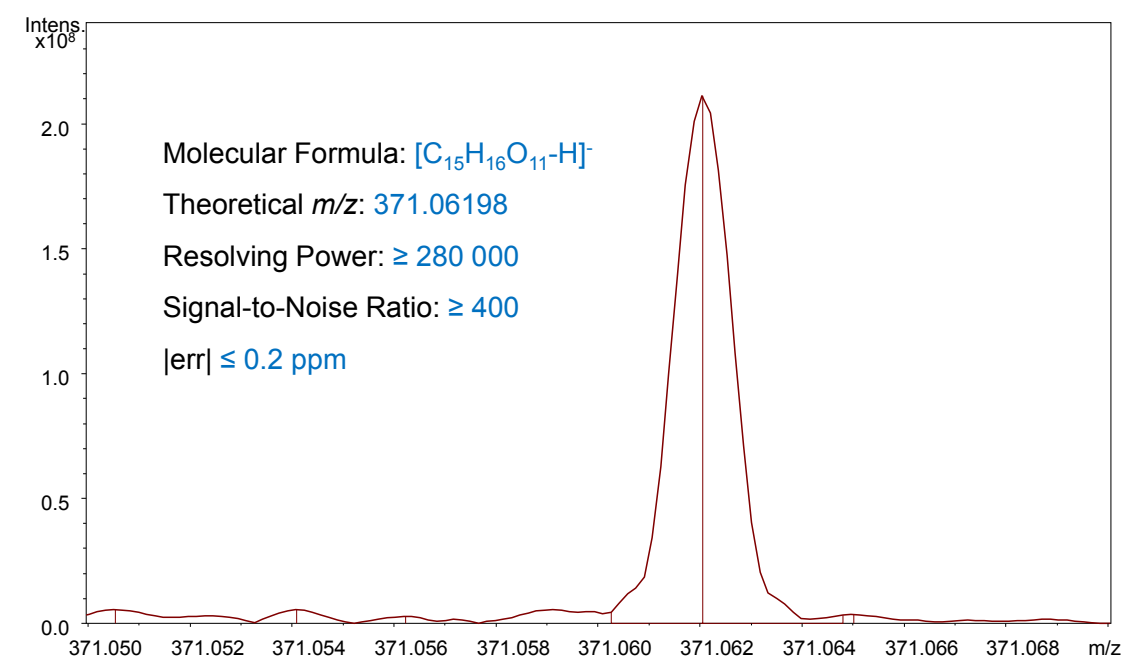

Figure 2. Mass scale-expanded segment at m/z 371.05 - 371.07 of SRFA

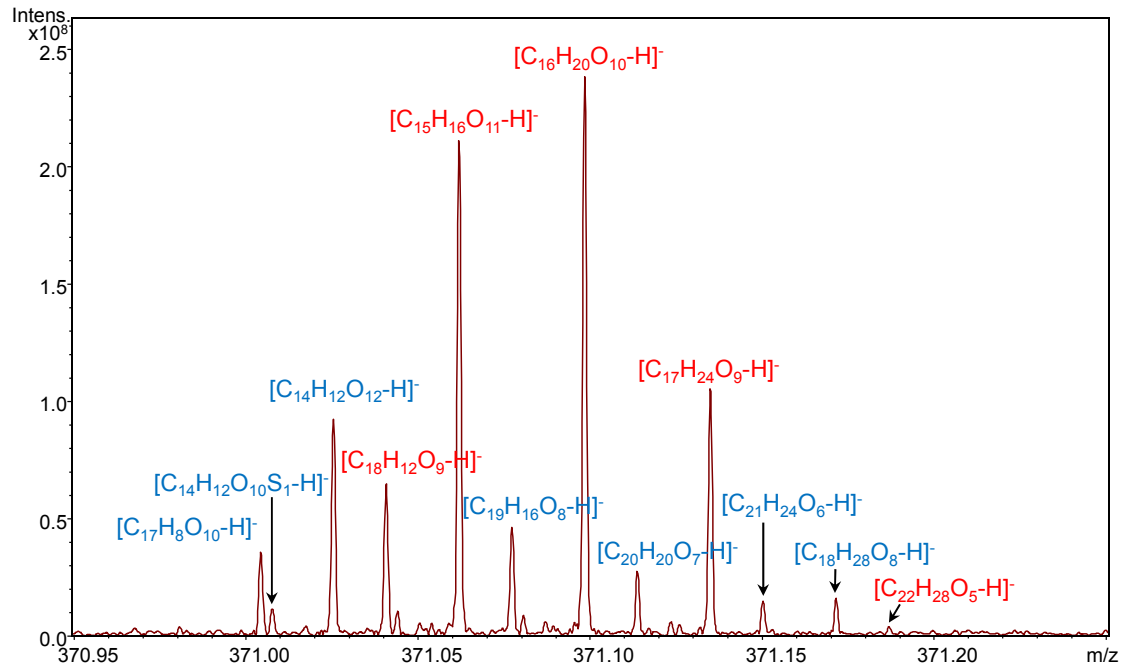

Figure 3. Mass scale-expanded segment at m/z 370.95 - 371.25 of SRFA

Table 1. Quantitative constraints on relative peak intensity at $\mathrm{m} / \mathrm{z} 371$

\begin{tabular}{cccl}
\hline $\begin{array}{c}\text { Theoretical } \\
\mathrm{m} / \mathrm{z}\end{array}$ & $\begin{array}{c}\text { Molecular } \\
\text { Formula }\end{array}$ & $\begin{array}{c}\text { Relative Intensity } \\
(\%)\end{array}$ & $\mathrm{S} / \mathrm{N}$ \\
\hline 371.04086 & {$\left[\mathrm{C}_{18} \mathrm{H}_{12} \mathrm{O}_{9}-\mathrm{H}\right]^{-}$} & $23 \pm 8$ & $\geq 120$ \\
371.06198 & {$\left[\mathrm{C}_{15} \mathrm{H}_{16} \mathrm{O}_{11}-\mathrm{H}\right]^{-}$} & $85 \pm 10$ & $\geq 400$ \\
371.09837 & {$\left[\mathrm{C}_{16} \mathrm{H}_{20} \mathrm{O}_{10}-\mathrm{H}\right]^{-}$} & 100 & $\geq 550$ \\
371.13476 & {$\left[\mathrm{C}_{17} \mathrm{H}_{24} \mathrm{O}_{9}-\mathrm{H}\right]^{-}$} & $54 \pm 10$ & $\geq 200$ \\
\hline
\end{tabular}




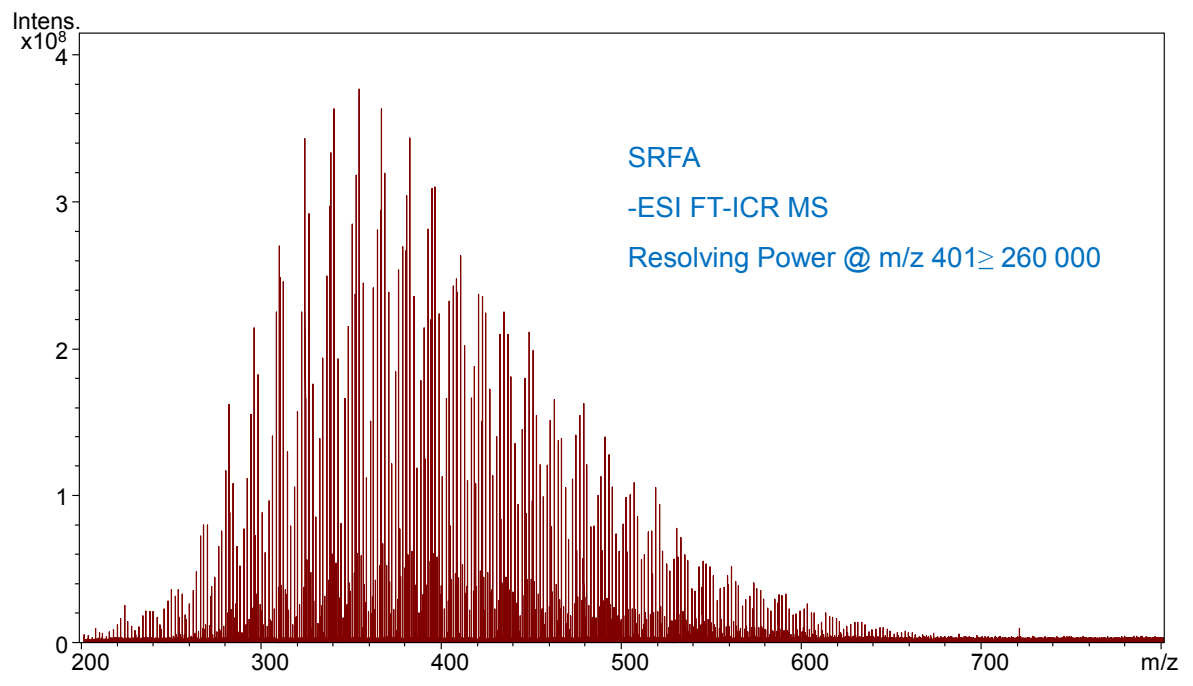

Figure 4. Broadband mass spectrum of SRFA

Table 2. Quantitative constraints on relative peak intensity of overall mass spectrum

\begin{tabular}{cccc}
\hline $\begin{array}{c}\text { Theoretical } \\
\mathrm{m} / \mathrm{z}\end{array}$ & Molecular Formula & $\begin{array}{c}\text { Relative Intensity } \\
(\%)\end{array}$ & $\mathrm{S} / \mathrm{N}$ \\
\hline 251.0197 & {$\left[\mathrm{C}_{11} \mathrm{H}_{8} \mathrm{O}_{7}-\mathrm{H}\right]^{-}$} & $8 \pm 5$ & $\geq 60$ \\
311.0772 & {$\left[\mathrm{C}_{14} \mathrm{H}_{16} \mathrm{O}_{8}-\mathrm{H}\right]^{-}$} & $55 \pm 15$ & $\geq 500$ \\
355.1034 & {$\left[\mathrm{C}_{16} \mathrm{H}_{20} \mathrm{O}_{9}-\mathrm{H}\right]^{-}$} & $95 \pm 5$ & $\geq 800$ \\
411.0932 & {$\left[\mathrm{C}_{18} \mathrm{H}_{20} \mathrm{O}_{11}-\mathrm{H}\right]^{-}$} & $70 \pm 10$ & $\geq 500$ \\
463.0517 & {$\left[\mathrm{C}_{20} \mathrm{H}_{16} \mathrm{O}_{13}-\mathrm{H}\right]^{-}$} & $50 \pm 15$ & $\geq 300$ \\
519.0418 & {$\left[\mathrm{C}_{22} \mathrm{H}_{16} \mathrm{O}_{15}-\mathrm{H}\right]^{-}$} & $25 \pm 15$ & $\geq 120$ \\
573.0524 & {$\left[\mathrm{C}_{25} \mathrm{H}_{18} \mathrm{O}_{16}-\mathrm{H}\right]^{-}$} & $12 \pm 8$ & $\geq 80$ \\
\hline
\end{tabular}

\section{Typical instrument parameters}

The typical instrument parameters that conform to the above mass spectral quality requirements are shown in Table 3. 
Table 3. Typical parameters of the FT-ICR MS

\begin{tabular}{|c|c|c|}
\hline Parameter & Values & Unite \\
\hline Data size & 2 & million points \\
\hline Mass range & $200-800$ & $\mathrm{Da}$ \\
\hline Average scans & 128 & number \\
\hline Transient length & 1.5379 & sec \\
\hline Flow rate & $180 \sim 250$ & $\mu \mathrm{L} / \mathrm{min}$ \\
\hline Capillary & $4200 \sim 3700$ & $\mathrm{~V}$ \\
\hline Spray Shield & $3700 \sim 3200$ & $\mathrm{~V}$ \\
\hline Neb gas Flow & $1.8 \sim 2.5$ & $\mathrm{~L} / \mathrm{min}$ \\
\hline Dry Gas Flow & $3.5 \sim 5$ & $\mathrm{~L} / \mathrm{min}$ \\
\hline Dry Temp & 200 & ${ }^{\circ} \mathrm{C}$ \\
\hline Capillary exit voltage & -300 & $\mathrm{~V}$ \\
\hline Deflector plate voltage & -280 & V \\
\hline Funnel 1 voltage & -160 & V \\
\hline Skimmer 1 voltage & -25 & V \\
\hline Funnel RF amplitude & 200 & Vpp \\
\hline Funnel 2 & -15 & $\mathrm{~V}$ \\
\hline Skimmer 2 & $-7 \sim-6$ & $\mathrm{~V}$ \\
\hline Q1 mass & 300 & $m / z$ \\
\hline Hexapole RF amplitude & 350 & Vpp \\
\hline Ion accumulation time in the hexapole & 0.001 & $\mathrm{sec}$ \\
\hline Accumulation time in the collision cell & $0.1 \sim 0.5$ & $\mathrm{sec}$ \\
\hline Ion flight time into the ICR cell & $1.0 \sim 1.2$ & $\mathrm{~ms}$ \\
\hline Collision voltage in the collision cell & 1.5 & V \\
\hline Analyzer entrance voltage & 2 & $\mathrm{~V}$ \\
\hline Side kick voltage & -10.5 & V \\
\hline Sidekick offset voltage & 6 & $\mathrm{~V}$ \\
\hline Front trap plate & $-0.9 \sim-0.95$ & $\mathrm{~V}$ \\
\hline Back trap plate voltage & $-0.95 \sim-1.0$ & $\mathrm{~V}$ \\
\hline Sweep excitation power & $13.5 \sim 15 \mathrm{~dB}$ & $\%$ \\
\hline
\end{tabular}




\section{Safety and environmental protection}

11.1 Methanol is toxic and related operations should be performed in a fume hood.

11.2 All waste reagents should be disposed of in accordance with the provisions of SY / T 6563-2003 and SY 6014-2010.

\section{Repeatability and reproducibility}

\subsection{Repeatability}

This method is performed three times at one times on SRFA under the normal and correct operation by the same operator and the same instrument. The repeatability of relative peak intensity at $m / z 371$ and overall mass spectrum is shown in Table 4 and 5, including average relative intensity, SD and RSD.

\subsection{Reproducibility}

The reproducibility was evaluated by results from 26 times analysis by different operators in different days in a period of six months. The reproducibility RSD of relative peak intensity at $\mathrm{m} / \mathrm{z}$ 371 is shown in Table 4 and 5.

\section{Report}

Provide raw data in .d format, SRFA report in .ppt format, and data file in .xls format.

SRFA report in .ppt format includes operating parameters of FT-ICR MS, Broadband mass spectrum, mass scale-expanded segment at m/z 371, and van Krevelen diagram of CHO-containing formulae.

Table 4. Repeatability and reproducibility of relative peak intensity at $m / z 371$.

\begin{tabular}{ccccccc}
\hline \multirow{2}{*}{$\begin{array}{c}\text { Theoretical } \\
\mathrm{m} / \mathrm{z}\end{array}$} & \multicolumn{3}{c}{ Repeatability } & \multicolumn{4}{c}{ Reproducibility } \\
\cline { 2 - 7 } & $\begin{array}{c}\text { Average Relative } \\
\text { Intensity (\%) }\end{array}$ & $\begin{array}{c}\text { SD } \\
(\%)\end{array}$ & $\begin{array}{c}\text { RSD } \\
(\%)\end{array}$ & $\begin{array}{c}\text { Average Relative } \\
\text { Intensity }(\%)\end{array}$ & $\begin{array}{c}\text { SD } \\
(\%)\end{array}$ & $\begin{array}{c}\text { RSD } \\
(\%)\end{array}$ \\
\hline 371.04086 & 20.49 & 0.17 & 0.84 & 25.15 & 3.89 & 15.45 \\
371.06198 & 80.02 & 4.15 & 5.18 & 83.82 & 6.17 & 7.36 \\
371.09837 & 100 & 0 & 0 & 100.00 & 0.00 & 0.00 \\
371.13476 & 52.61 & 0.48 & 0.91 & 51.58 & 5.23 & 10.14 \\
\hline
\end{tabular}


Table 5. Repeatability and reproducibility of relative intensity of overall mass peaks.

\begin{tabular}{ccccccc}
\hline \multirow{2}{*}{$\begin{array}{c}\text { Theoretical } \\
\mathrm{m} / \mathrm{z}\end{array}$} & \multicolumn{3}{c}{ Repeatability } & \multicolumn{4}{c}{ Reproducibility } \\
\cline { 2 - 7 } & $\begin{array}{c}\text { Average Relative } \\
\text { Intensity (\%) }\end{array}$ & $\begin{array}{c}\text { SD } \\
(\%)\end{array}$ & $\begin{array}{c}\text { RSD } \\
(\%)\end{array}$ & $\begin{array}{c}\text { Average Relative } \\
\text { Intensity (\%) }\end{array}$ & $\begin{array}{c}\text { SD } \\
(\%)\end{array}$ & $\begin{array}{c}\text { RSD } \\
(\%)\end{array}$ \\
\hline 251.01973 & 7.56 & 1.50 & 19.78 & 8.50 & 2.42 & 28.43 \\
311.07724 & 58.68 & 1.03 & 1.75 & 60.32 & 6.68 & 11.07 \\
355.10339 & 93.77 & 1.40 & 1.49 & 92.36 & 4.92 & 5.33 \\
411.09324 & 68.46 & 1.30 & 1.89 & 68.83 & 4.55 & 6.60 \\
463.05171 & 42.16 & 0.59 & 1.41 & 45.65 & 6.50 & 14.24 \\
519.0418 & 23.32 & 0.53 & 2.27 & 24.40 & 5.77 & 23.65 \\
573.05243 & 11.38 & 0.87 & 7.67 & 11.86 & 3.92 & 33.03 \\
\hline
\end{tabular}

